\title{
Abnormalities of Peripheral Nerve Conduction in Relation to Thiamine Status in Alcoholic Patients
}

\author{
Monique L. D’Amour, Julie Bruneau and Roger F. Butterworth
}

\begin{abstract}
Thiamine status was evaluated using the erythrocyte transketolase activation assay in 20 alcoholic patients admitted on a voluntary basis to a Detoxification Unit. Electromyographic evaluation revealed significant reductions of motor and sensory conduction velocities in the alcoholic group. $38 \%$ of alcoholic patients had at least one abnormal peripheral nerve conduction parameter. Findings were consistent with an axonal type of neuropathy. 30\% of alcoholic patients showed significant erythrocyte transketolase activation deficits indicative of severe thiamine deficiency. In the case of peroneal nerve, reduced conduction velocities were negatively correlated with abnormal transketolase parameters. These findings are consistent with a contributory (but not exclusive) role of thiamine deficiency in the pathogenesis of alcoholic peripheral neuropathy. Deficiencies of other vitamins as well as direct neurotoxic effects of alcohol could also be involved in this phenomenon.

RÉSUMÉ: L'étude a permis d'évaluer l'état thiaminique de 20 malades éthyliques admis électivement à une unité de désintoxication. L'évaluation électromyographique a montré un ralentissement significatif des vitesses de conduction motrice et sensitive. La diminution d'amplitude des réponses évoquées est compatible avec une neuropathie axonale. $38 \%$ de ces patients avaient au moins une vitesse de conduction anormale et $30 \%$ un défaut d'activation de la transcétolase érythrocytaire compatible avec une déficience sévère en thiamine. En ce qui a trait au nerf sciatique poplite externe, le ralentissement de la vitesse de conduction a révélé une corrélation négative avec les paramètres de la transcétolase. Ces anomalies suggèrent un rôle contributif du moins, sinon exclusif, de la déficience en thiamine dans la pathogénése de la neuropathie éthylique. Une déficience additionnelle vitamique autre ou encore l'effet de l'alcool lui-même peut-être totalement exclus pour le moment.
\end{abstract}

Can. J. Neurol. Sci. 1991; 18: 126-128

Peripheral neuropathy remains a major neurological complication of chronic alcoholism. Recovery from alcoholic peripheral neuropathy is slow and often incomplete ${ }^{1.2}$ so that early diagnosis and prompt appropriate therapeutic intervention may be essential. It has generally been assumed that alcoholic peripheral neuropathy results from thiamine deficiency or multiple vitamin deficiencies. The exact cause has not been determined. In one study, $86 \%$ of alcoholics with clinical signs of peripheral neuropathy had significantly decreased blood thiamine levels.' However, concomitant deficiencies of other vitamins, including vitamin $B_{6}$ and pantothenic acid, deficiencies of which are known to result in peripheral neuropathy, were also observed in these patients.

The present study was undertaken in order to establish whether or not a correlation exists between the severity of electromyographically-defined signs of peripheral neuropathy and the degree of severity of thiamine deficiency in alcoholic patients. The assessment of thiamine status in humans may require the measurement of thiamine esters or thiamine enzymes rather than whole blood thiamine. ${ }^{3}$

In the present study, thiamine status was assessed in a population of alcoholic patients using the erythrocyte transketolase activation assay. 3.4

\section{Materials and Methods}

20 alcoholic subjects admitted to the Detoxification Unit, Hôpital St-Luc, were studied. Patients were admitted on a voluntary basis for treatment of chronic alcoholism. All had a history of alcohol intake of 10 years or more defined as a daily consumption of more than $100 \mathrm{gm}$ of alcohol. Systematic nutritional assessments were not performed. However, no patients showed signs of gross malnutrition; in no cases were there any significant medical problems related to alcoholism such as alcoholic cirrhosis, pancreatitis or Wernicke's Encephalopathy. For the purposes of the present study, patients receiving daily vitamin supplements were excluded.

From the Neurology Service (M.L.D.), Detoxification Unit (J.B.), Laboratory of Neurochemistry (R.F.B.), André-Viallet Clinical Reserach Center, Hôpital Saint-Luc (University of Montreal), Montreal 
Studies were done in the first few days following admission. The mean age of the subjects was 46 years (range 31 to 67). A control group consisted of 20 healthy volunteers composed of hospital personnel, mean age 38 years (range 21 to 50 ).

An electromyographic study (EMG) was undertaken with a TECA, TE-4 machine. It included determination of nerve conduction velocities of motor median, ulnar, peroneal, tibial nerves and orthodromic conduction velocities of sensory median (index), ulnar (fifth finger) and sural nerves. Amplitude of evoked responses was measured. Needle EMG of corresponding muscles was also performed.

Concomitantly, blood was drawn for red blood cell transketolase activation assay. 5

Statistical anyalysis for EMG and biochemical data were done by unpaired student- $t$ test and Fisher exact test, 1 tail.

\section{RESULTS}

Clinical evaluation revealed $15 / 20$ patients with minimal sensory or motor symptoms or signs (numbness in the feet, mild decreased vibratory perception, decreased ankle jerks and mild atrophy of distal muscles). 5/20 patients showed no such abnormalities. Routine blood biochemistry studies revealed no anemia, normal protein values and mild elevation of liver enzymes in some patients.

Erythrocyte transketolase (TKA) activities, measured in the presence of excess thiamine pyrophosphate were found to be significantly decreased in alcoholic patients (Figures 1 and 2). $38 \%$ of the patients had at least one abnormal nerve conduction parameter and $35 \%$ had an abnormal value of TKA or TPP-effect.

In Table 1, values of nerve conduction velocity for each nerve studied are listed. They are significantly reduced in the patients compared to the control group. Compound muscle action potential amplitudes in alcoholics were reduced on average by $26 \%$ (Table 2 ). Reduced recruitment of motor units followed

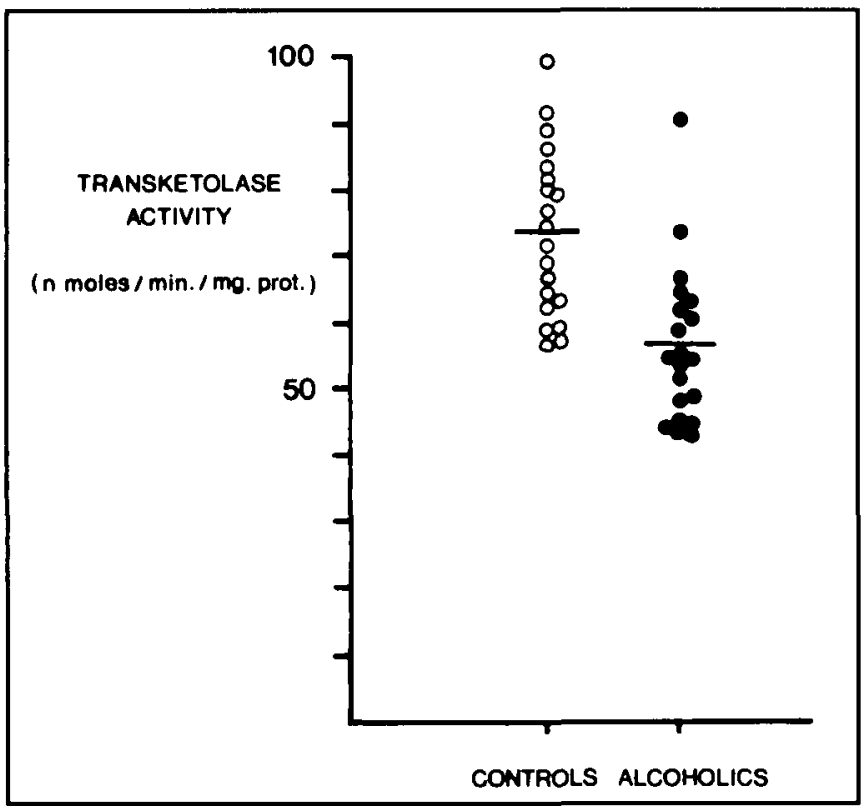

Figure I - Transketolase activities in red blood cell hemolysates from alcoholic patients and controls. Horizontal bars represent mean values; mean for alcoholic patients significantly less than control mean $(p<0.01)$ by Student's T test.

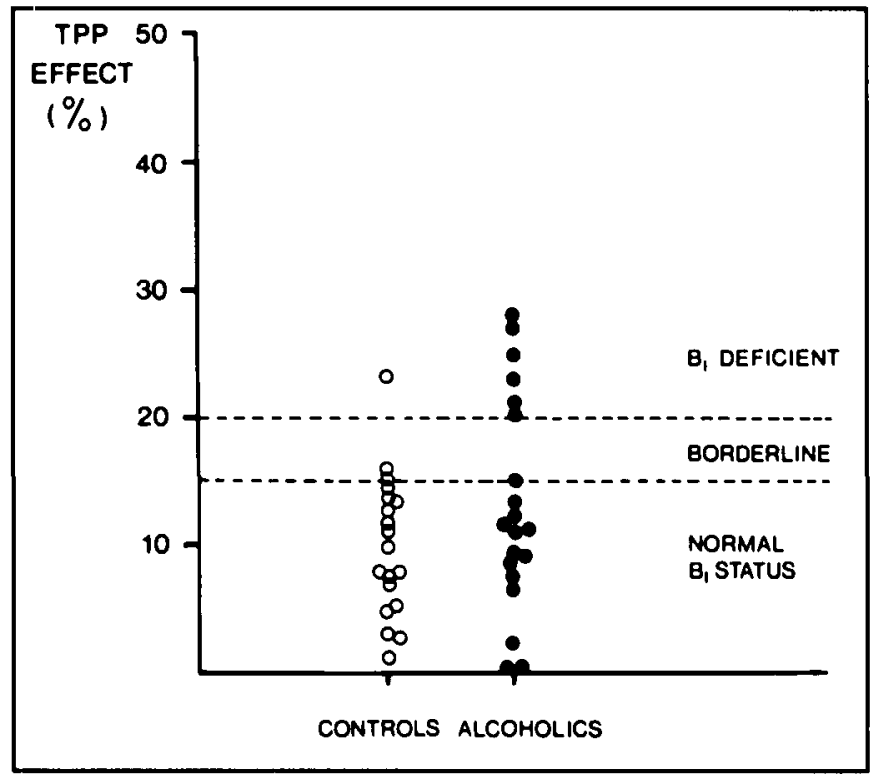

Figure 2 - Transketolase activation ("TPP Effect") values in red blood cell hemolysates from alcoholic patients and controls.

Table 1: Sensory and Motor Nerve Conduction Velocities in Normal Subjects and Alcoholic Patients

\begin{tabular}{lcc}
\hline \hline Nerve & $\begin{array}{c}\text { Nerve conduction velocity (M/sec) } \\
\text { Normal subjects (20) }\end{array}$ & Alcoholic patients (20) \\
\hline Motor & & \\
$\quad$ Median & $65.0 \pm 5.3$ & $61.5 \pm 8.3^{*}$ \\
Ulnar & $66.8 \pm 4.9$ & $61.2 \pm 7.1^{* *}$ \\
Peroneal & $56.0 \pm 5.8$ & $48.3 \pm 8.0^{* *}$ \\
Posterior tibial & $53.0 \pm 4.8$ & $48.2 \pm 7.5^{* *}$ \\
Sensory & & \\
$\quad$ Median & $63.4 \pm 4.4$ & $56.1 \pm 8.3^{* *}$ \\
Ulnar & $60.2 \pm 6.4$ & $55.9 \pm 6.4^{*}$ \\
Sural & $55.5 \pm 5.1$ & $51.8 \pm 7.6$ \\
\hline
\end{tabular}

Nerve conduction velocities are means \pm S.D. (number of patients in parentheses). Values significantly different from normal are indicated by ${ }^{*} \mathrm{p}<0.05,{ }^{* *} \mathrm{p}<0.01$ by student's $\mathrm{T}$ test.

Table 2: Amplitude of Sensory and Motor Evoked Responses in Normal Subjects and Alcoholic Patients

\begin{tabular}{lcc}
\hline \hline & \multicolumn{2}{c}{ Amplitude of evoked response } \\
Nerve & Normal subjects (20) & Alcoholic patients (20) \\
\hline Motor nerves (mV) & & \\
$\quad$ Median & $14.2 \pm 4.1$ & $9.96 \pm 4.1^{*}$ \\
Ulnar & $12.8 \pm 3.2$ & $12.5 \pm 3.7$ \\
Peroneal & $8.4 \pm 3.7$ & $5.7 \pm 2.2^{*}$ \\
Posterior tibial & $16.6 \pm 6.2$ & $13.9 \pm 6.8$ \\
Sensory $(\mu \mathrm{V})$ & & \\
Median & $24.9 \pm 12.5$ & $15.8 \pm 5.7^{*}$ \\
Ulnar & $15.1 \pm 6.2$ & $11.5 \pm 6.4$ \\
Sural & $10.2 \pm 4.7$ & $9.5 \pm 5.3$ \\
\hline
\end{tabular}

Values are means of \pm S.D. (number of patients in parentheses). Significant differences from control values are indicated by $* p<0.05$ by student's $T$ test. 
accordingly. 3/20 patients had fibrillations and positive sharp waves in their distal muscles. These overall findings suggest an axonal type of neuopathy. 6

In the case of peroneal nerve, reduced conduction velocities were negatively correlated with TPP effect values $(p \leq 0.05)$ using Fisher 1 tail exact test. Mean values of peroneal nerve conduction velocities in these 7 patients, mean age 40 years, was $43.4 \mathrm{M} / \mathrm{sec}$. No significant correlations were observed for other nerves (motor: median $p=0.20$; ulnar $p=0.50$; posterior tibial $p=0.59$; sensory: median $p=0.47$; ulnar $p=0.10$; sural $\mathrm{p}=0.60)$.

\section{Discussion}

Results of the present study reveal, in alcoholic patients admitted on a voluntary basis to a Detoxification Unit, abnormal nerve conduction velocities and abnormal thiamine status. These patients had minimal clinical signs of neuropathy. Routine biochemical studies did not show significant abnormalities. Clinically, there were no indications of other causes or neuropathy or of Wernicke's encephalopathy.

Electromyographic (EMG) evaluation showed significantly reduced motor and sensory conduction velocities in the alcoholic group as compared to the control group. Amplitudes or evoked responses followed a similar pattern. EMG abnormalities observed were comparable to those of previously published studies. ${ }^{7-9}$ Findings are consistent with an axonal type of neuropathy. Thiamine-deficiency in rats has been shown to result in increased axonal transport and reduced periperal nerve conduction velocities. ${ }^{10}$

Thiamine deficiency defined as erythrocyte transketolase activities in excess of $20 \%$ was observed in $6 / 20$ alcoholic patients in the present study. Mean TKA and TPP effect values were significantly different in the alcoholic and control group. Correlations between peripheral nerve conduction velocities and thiamine status, however, were unimpressive, with the exception of peroneal nerve in which a significant association between TKA and TPP effect values and conduction velocities was observed.

It has frequently been proposed that a direct toxic effect of alcohol, rather than nutritional deficiency, is responsible for alcoholic peripheral neuropathy. "In this latter study, 23 of 37 alcoholic patients had adequate dietary intake and blood thiamine levels, measured in one-third of the patients, were normal. However, as pointed out by Victor et al. ${ }^{2}$ such criteria may not be sufficiently strict to rule out a thiamine deficiency etiology. Blood thiamine levels do not accurately reflect thiamine status in humans. ${ }^{3}$ Furthermore, other studies of the effects of the consumption of large guantities of alcohol in both humans and experimental animals with adequate vitamin intake have failed to reveal any signs of peripheral nerve dysfunction. 8.12

Thus, the identity of the nutritional factor(s) responsible for peripheral nerve dysfunction in alcoholics remains unclear. Results of the present study suggest a contributory (but, clearly, not exclusive) role of thiamine deficiency, at least in the patho- genesis of damage to large diameter fibres of long peripheral nerves. However, the alcoholic patient is not deficient solely in vitamin $B_{1}$; deficiencies of $B_{6}, B_{12}$, folate and pantothenic acid have also been described in chronic alcohol abusers. 1,13 Furthermore, deficiencies of $\mathrm{B}_{6}$ and of pantothenic acid have been shown to result in clinical signs of peripheral neuropathy in humans. ${ }^{1,14}$ Whether or not deficiencies of these vitamins play a significant role in the pathogenesis of alcoholic peripheral neuropathy is presently under investigation in our research unit.

\section{ACKNOWLEDGEMENTS}

These studies were supported by grants from The Medical Research Council of Canada, La Fondation Jean Lapointe, The Alcoholic Beverages Medical Research Foundation (USA) and L'Université de Montréal (CAFIR). We are grateful to Dr. Gilles Pomier Layrargues for his assistance with the study design and to Dominique D. Roy for preparation of the manuscript.

\section{REFERENCES}

I. Fennelly J, Frank O, Baker H, et al. Peripheral neuropathy of the alcoholic: I, aetiological role of aneurin and other B-complex vitamins. Brit Med J 1964; 2: 1290-1292.

2. Victor M, Adams RD and Collins GH. The Wernicke-Korsakoff Syndrome and related neurologic disorders due to alcoholism and malnutrition, 2nd Ed. Contemporary Neurology Series, F.A. Davis, Philadelphia 1989.

3. Warnock LG, Prudhomme CR and Wagner C. The determination of thiamine pyrophosphate in blood and other tissues and its correlation with erythrocyte transketolase activity. J Nutr 1978; 108: 421-427.

4. Butterworth RF. Thiamin malnutrition and brain development. $m$ : Rassin DK, Haber B, Drujan B, eds. Basic and Clinical Aspects of Nutrition and Brain Development. New York: Alan R. Liss, Inc. 1987; 279-296.

5. Butterworth RF, Giguère JF and Besnard AM. Activities of thiamine-dependent enzymes in two experimental models of thiamine-deficiency encephalopathy. Neurochem Res 1985; 10: 1417-1428.

6. Kelly JJ Jnr. The electrodiagnostic findings in peripheral neuropathy associated with monoclonal gammopathy. Muscle \& Nerve 1983; 6: 504-509.

7. Mawdsley C, Mayer RF. Nerve conduction in alcoholic neuropathy. Brain 1965; 88: 335-356.

8. Mayer RF. Peripheral nerve conduction in alcoholics. Psychosom Med 1966; 28: 475.

9. Lefebvre-D'Amour M, Shahani BT, Young RR, et al. Importance of studying sural conduction and late responses in the evaluation of alcoholic subjects. Neurology 1979; 29: 1600-1604.

10. Mc Lane JA, Khna T, Held IR. Increased axonal transport in peripheral nerves of thiamine-deficient rats. Exp Neurol 1987; 95: 482491.

11. Behse F and Buchthal F. Alcoholic neuropathy: clinical electrophysiological and biopsy findings. Ann Neurol 1977; 2: 95-110.

12. Juntunen J, Teravainen $\mathrm{H}$, Eriksson K, et al. Peripheral neuropathy and myopathy, An experimental study on rats on alcohol and variable dietary thiamine. Virchows Arch Pathol [Anat Histol] 1979; 383: 241-242.

13. Butterworth RF. Vitamin deficiencies and brain development. In: van Gelder NM, Butterworth RF, Drujan B, eds. Malnutrition and the Infant Brain. New York: Alan R. Liss, Inc. 1990.

14. Bean WB, Hodges RE and Daun KE. Pantothenic acid deficiency induced in human subjects. J Clin Invest 1955; 34: 1073-1084. 